\title{
Fixed-Combination Gels of Adapalene and Benzoyl Peroxide Provide Optimal Percutaneous Absorption Compared to Monad Formulations of These Compounds: Results from Two In Vitro Studies
}

\author{
Hanan Osman-Ponchet · Karine Sevin • Alexandre Gaborit • \\ Nathalie Wagner · Michel Poncet
}

Received: September 23, 2016 / Published online: November 30, 2016

(C) The Author(s) 2016. This article is published with open access at Springerlink.com

\section{ABSTRACT}

Introduction: Adapalene

$0.1 \% /$ benzoyl peroxide $2.5 \%(0.1 \% \mathrm{~A} / \mathrm{BPO})$ and adapalene $0.3 \% / \mathrm{BPO} \quad 2.5 \% \quad(0.3 \% \quad \mathrm{~A} / \mathrm{BPO})$ gels are fixed-combination options for the topical treatment of acne. However, the active compounds of these combinations are also available as monads, to be used in association or as monotherapy. These two in vitro studies determined the effect of different treatment regimens on the percutaneous absorption of adapalene $(0.1 \%$ and $0.3 \%)$ gels and BPO $2.5 \%$ gel in ex vivo human skin.

Methods: In vitro percutaneous absorption studies were conducted using full-thickness human skin from six donors. Treatment regimens included the application of $0.1 \%$ $\mathrm{A} / \mathrm{BPO}, 0.3 \% \mathrm{~A} / \mathrm{BPO}$, or four free-combination regimens of the monads. Skin samples were

Enhanced content To view enhanced content for this article go to http://www.medengine.com/Redeem/ 9627F060237164D6.

H. Osman-Ponchet $(\bowtie) \cdot$ K. Sevin · A. Gaborit . N. Wagner · M. Poncet Galderma R\&D, Les Templiers, 2400 Route des Colles, BP87, 06902 Sophia Antipolis, France e-mail: hanan.osman-ponchet@galderma.com incubated for $24 \mathrm{~h}$. Concentrations of adapalene and BPO equivalent (BPO-eq) (i.e. benzoic acid after chemical transformation of BPO) were measured using high-performance liquid chromatography. Comparison of regimens was performed using a bioequivalence criterion (estimated ratio bewteen 0.8 and 1.25).

Results: The fixed combination $0.3 \%$ A/BPO regimen demonstrated more than three times higher absorption of adapalene versus the fixed-combination $0.1 \% \mathrm{~A} / \mathrm{BPO}$. Based on the bioequivalence acceptance criterion, all four free-combination regimens were different from $0.1 \% \mathrm{~A} / \mathrm{BPO}$ and $0.3 \% \mathrm{~A} / \mathrm{BPO}$, with higher adapalene release delivered by the fixed combinations versus the free combinations. For BPO-eq, the results showed that the free-combination regimens where adapalene $0.1 \%$ was applied first were different from $0.1 \%$ $\mathrm{A} / \mathrm{BPO}$, with lower BPO-eq release delivered by these regimens compared to the fixed combination. The regimen adapalene $0.3 \%$ for $10 \mathrm{~h}$ followed by BPO 2.5\% delivered lower BPO-eq release compared to the fixed combination.

Conclusion: The fixed-combination A/BPO gels provide optimal percutaneous absorption of the 
active compounds compared to free combinations of adapalene $0.1 \%$, adapalene $0.3 \%$, and BPO 2.5\%. The higher concentration of adapalene in the $0.3 \% \mathrm{~A} / \mathrm{BPO}$ gel and the resulting higher absorption may explain higher clinical efficacy.

Keywords: Adapalene/benzoyl peroxide gel; Fixed combination; In vitro; Optimal percutaneous absorption

\section{INTRODUCTION}

Acne is a chronic disease which results in significant psychological burden and reduced quality of life for patients [1]. The disease has been ranked as the eighth most prevalent disease worldwide [2]. Prompt and effective treatment is crucial for the prevention of acne sequelae [3]. The current armamentarium for the topical treatment of acne includes an array of agents which can be used in combination [4]. A combination recommended by international guidelines for the topical treatment of acne involves the use of a retinoid, such as adapalene, with benzoyl peroxide (BPO) [4-6].

Adapalene possesses comedolytic, anticomedogenic, and anti-inflammatory properties [7-11]. The efficacy and safety of adapalene $0.1 \%$ gel has been demonstrated in clinical studies [10-12]. Further studies have reported that a higher concentration of the formulation (adapalene $0.3 \%$ gel) shows superior efficacy and a similar tolerability profile compared to adapalene $0.1 \%$ gel and vehicle [13, 14]. Clinical data have also demonstrated that adapalene $0.3 \%$ gel was safe and effective in the long-term (12 months) treatment of patients with acne [15]. BPO is the antimicrobial agent of choice due to its bactericidal properties against Propionibacterium acnes (P. acnes), and absence of antibiotic resistance [16-18]. Formulations of both active compounds are available as monads, to be used in association or as monotherapy for the treatment of acne.

Adapalene $0.1 \% / \mathrm{BPO} \quad 2.5 \%$ gel (Epiduo $^{\circledR}$; Galderma, Lausanne, Switzerland) (0.1\% $\mathrm{A} / \mathrm{BPO}$ ) is an antibiotic-free, fixed-dose combination of adapalene and $\mathrm{BPO}$, which is efficacious in mild-to-moderate acne [16-19]. Data from randomized clinical studies demonstrated that $0.1 \% \quad \mathrm{~A} / \mathrm{BPO}$ provided synergistic and significantly greater efficacy than its monads in the treatment of acne, with an acceptable safety profile [17-21]. Recent clinical evidence, demonstrated the significantly greater efficacy of higher concentration adapalene $0.3 \% / \mathrm{BPO} \quad 2.5 \%$ fixed-dose topical gel $\left(\right.$ Epiduo $^{\circledR}$ Forte; Galderma) (0.3\% A/BPO) compared to vehicle as well as a good safety profile in patients with moderate-to-severe acne, increasing treatment options [22]. Although it has been demonstrated that the fixed combination can provide superior success in the reduction of acne lesions and an improvement in the clinical condition of patients compared to that of its monads [16-21], there are no data on the drug bioavailability and bioequivalence of these agents. In vitro percutaneous absorption studies could be used for the comparison of these treatment regimens $[23,24]$.

The objective of these two studies was to determine the effect of different treatment regimens on the percutaneous absorption of adapalene $(0.1 \%$ and $0.3 \%)$ gel and BPO $2.5 \%$ gel in ex vivo human skin.

\section{METHODS}

In vitro percutaneous absorption studies were conducted using full-thickness human skin 
from three donors (per study), mounted on polycarbonate membrane inserts of 6-well culture plates. Skin samples of about $2 \times 2 \mathrm{~cm}$ were cut out from the isolated skin after careful removal of subcutaneous fat. Skin samples were then carefully transferred into six-well plates on a Transwell ${ }^{\circledR}$ insert which allows contact of the receptor fluid to the dermal side of the skin sample, while the stratum corneum remains exposed to the air. Glass cylinders of $1 \mathrm{~cm}^{2}$ surface were glued to the epidermal side of the skin sample using cyanoacrylate-based glue. This keeps the skin flat and in constant contact with the receptor liquid and prevents bending.

A dose of $10 \mathrm{mg} / \mathrm{cm}^{2}$ of each formulation was applied on the skin surface (application area of $1 \mathrm{~cm}^{2}$ ) and $2 \mathrm{~mL}$ of phosphate buffer saline were added in the receptor compartment. A dose of $10 \mathrm{mg} / \mathrm{cm}^{2}$ was chosen taking into account the clinical use conditions $(1-5 \mathrm{mg} /$ $\mathrm{cm}^{2}$ ) and the sensitivity of analytical methods.

The $0.1 \%$ A/BPO study included the following treatment regimens:

- $0.1 \% \mathrm{~A} / \mathrm{BPO}$ gel

- BPO $2.5 \%$ gel for $10 \mathrm{~min}$ followed by adapalene $0.1 \%$ gel.

- Adapalene $0.1 \%$ gel for $10 \mathrm{~min}$ followed by BPO $2.5 \%$ gel.

- BPO 2.5\% gel for $10 \mathrm{~h}$ followed by adapalene $0.1 \%$ gel.

- Adapalene $0.1 \%$ gel for $10 \mathrm{~h}$ followed by BPO $2.5 \%$ gel.

The $0.3 \%$ A/BPO study included the following treatment regimens:

- $0.3 \% \mathrm{~A} / \mathrm{BPO}$ gel

- BPO $2.5 \%$ gel for $10 \mathrm{~min}$ followed by adapalene $0.3 \%$ gel.

- Adapalene $0.3 \%$ gel for $10 \mathrm{~min}$ followed by BPO 2.5\% gel.

- BPO 2.5\% gel for $10 \mathrm{~h}$ followed by adapalene $0.3 \%$ gel.
- Adapalene $0.3 \%$ gel for $10 \mathrm{~h}$ followed by BPO $2.5 \%$ gel.

The sequential application of monads separated by $10 \mathrm{~min}$ was chosen in order to simulate the use of both monads in association at the same time by the patient. The sequential application of monads separated by $10 \mathrm{~h}$ was chosen in order to simulate the use of monad as monotherapy. This interval was chosen to mimic morning/evening application of each monad in patient use conditions while respecting technical and operational constraints of the ex vivo test.

Skin samples were incubated $\left(37^{\circ} \mathrm{C}\right.$ and $5 \%$ $\mathrm{CO}_{2}$ ) for $24 \mathrm{~h}$. Each condition was performed in triplicate for each of the three donors (i.e. $n=9$ ). Concentrations of adapalene and BPO equivalent (BPO-eq) (i.e. benzoic acid after chemical transformation of $\mathrm{BPO}$ ) were measured using high-performance liquid chromatography.

Comparison between the different treatment regimens was performed using the geometric mean ratio of test/reference treatment approach a (bioequivalence criterion estimated ratio of geometric means between 0.8 and 1.25).

\section{Compliance with Ethics Guidelines}

This article does not contain any new studies with human or animal subjects performed by any of the authors.

\section{RESULTS}

\section{1\% A/BPO Study}

\section{Skin Characteristics}

Three full-thickness skin samples from three female donors, aged 56-79 years, were used in the study. The skin sample thickness ranged between 1.7 and $2.2 \mathrm{~mm}$. 


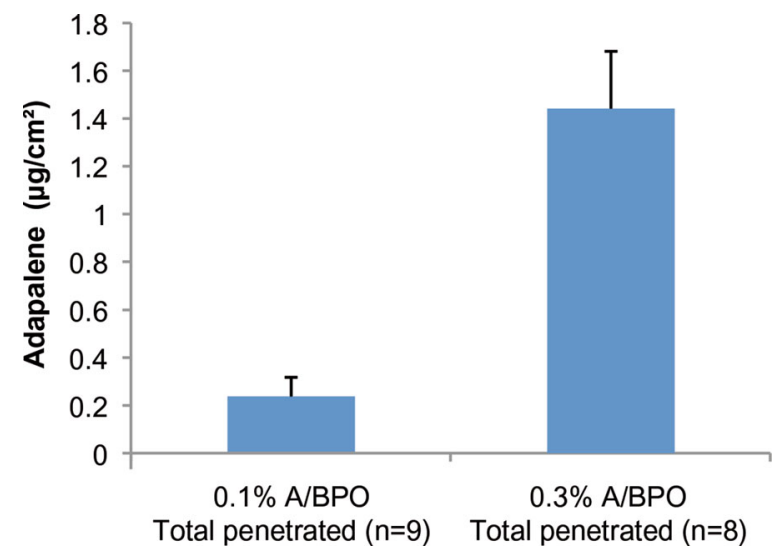

Fig. 1 Adapalene: total penetrated into skin $\left(\mu \mathrm{g} / \mathrm{cm}^{2}\right)$ (mean and standard error of the mean)

\section{Adapalene Release}

Figure 1 illustrates the total penetrated adapalene for $0.1 \% \mathrm{~A} / \mathrm{BPO}$. Based on the bioequivalence acceptance criterion, the results showed that all free-combination regimens were different from $0.1 \% \mathrm{~A} / \mathrm{BPO}$ gel, with geometric mean ratios outside the acceptance interval of $80-120 \%$ (Fig. 2). The $0.1 \%$ A/BPO gel showed higher adapalene release compared to all monad formulations.

\section{BPO-eq Release}

Figure 3 illustrates the total penetrated BPO-eq for $0.1 \% \mathrm{~A} / \mathrm{BPO}$. According to the bioequivalence

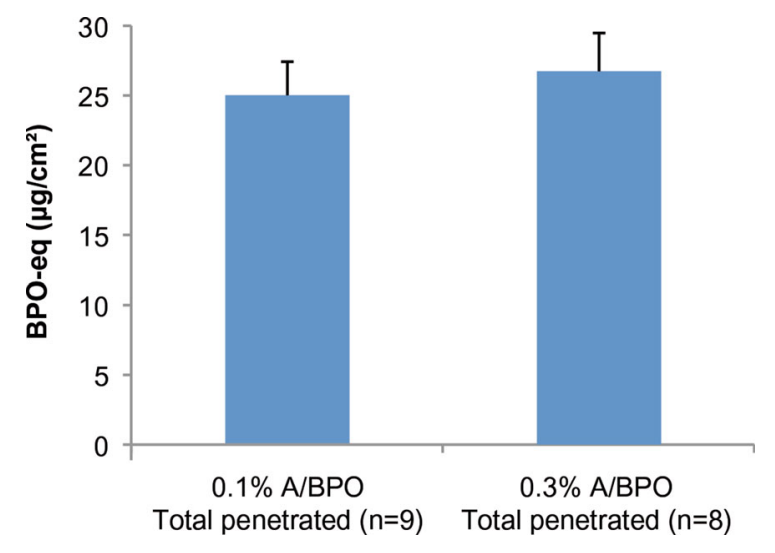

Fig. 3 BPO-eq: total penetrated into skin $\left(\mu \mathrm{g} / \mathrm{cm}^{2}\right)($ mean and standard error of the mean)

acceptance criterion, the free-combination regimens with application of adapalene $0.1 \%$ gel prior to $\mathrm{BPO} 2.5 \%$ gel were different from $\mathrm{A} / \mathrm{BPO}$ gel treatment (Fig. 4). The $0.1 \%$ A/BPO gel showed higher BPO-eq release compared to monad formulations.

\section{3\% A/BPO Study}

\section{Skin Characteristics}

Three full-thickness skin samples from 2 male and 1 female donors, aged 31-55 years, were used in the study. The skin sample thickness was between 1.6 and $3.2 \mathrm{~mm}$.

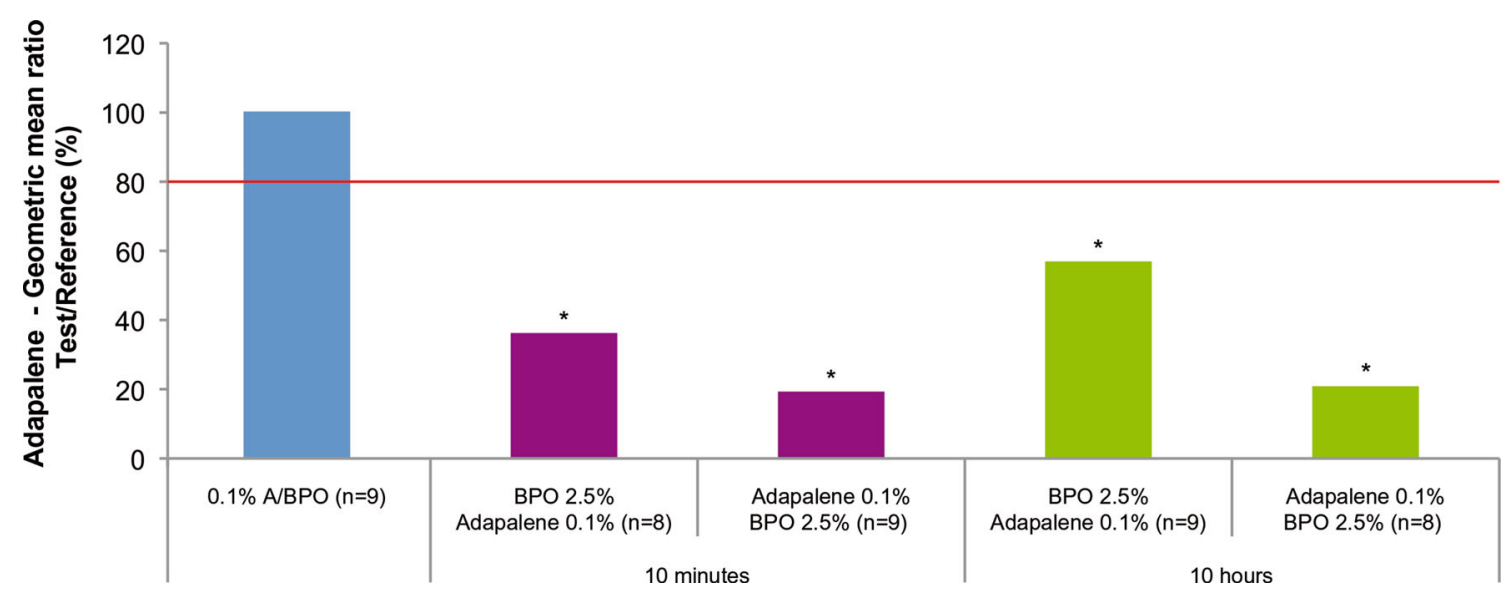

Fig. 2 Adapalene: comparison between treatment regimens (geometric mean ratio, \%). Asterisk outside the acceptance interval of $80-125 \%(<80 \%)$ 


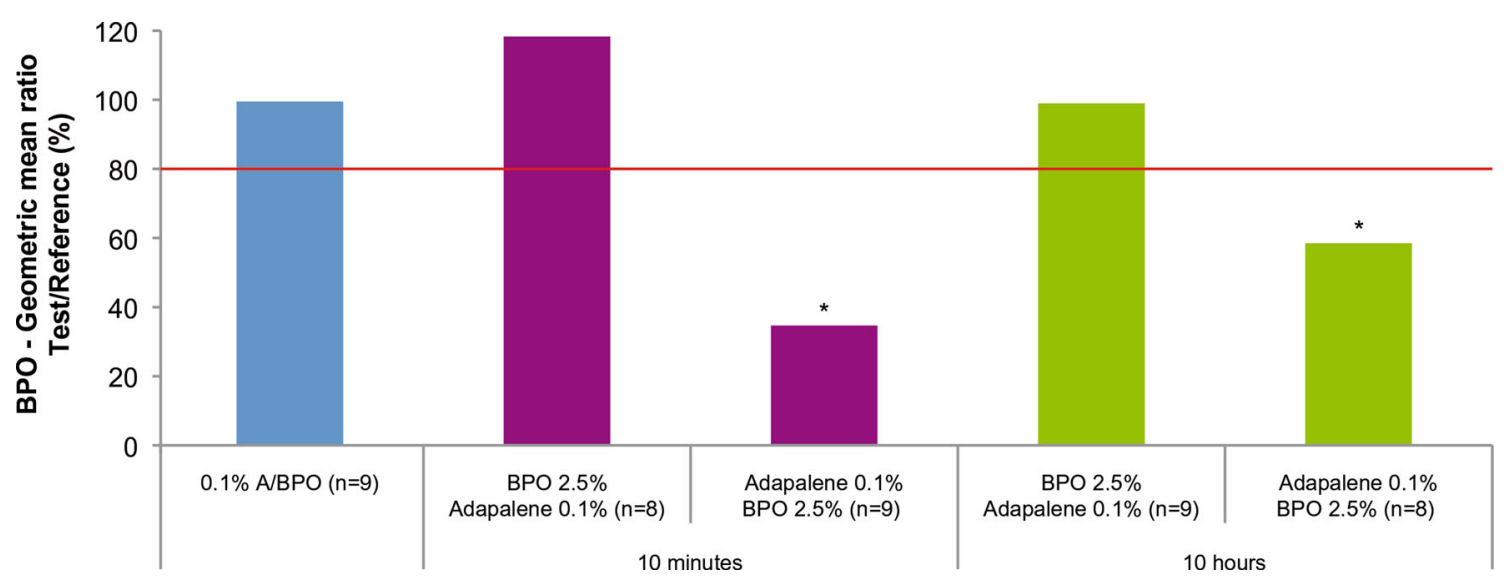

Fig. 4 BPO-eq: comparison between treatment regimens (geometric mean ratio, \%). Asterisk outside the acceptance interval of $80-125 \%(<80 \%)$

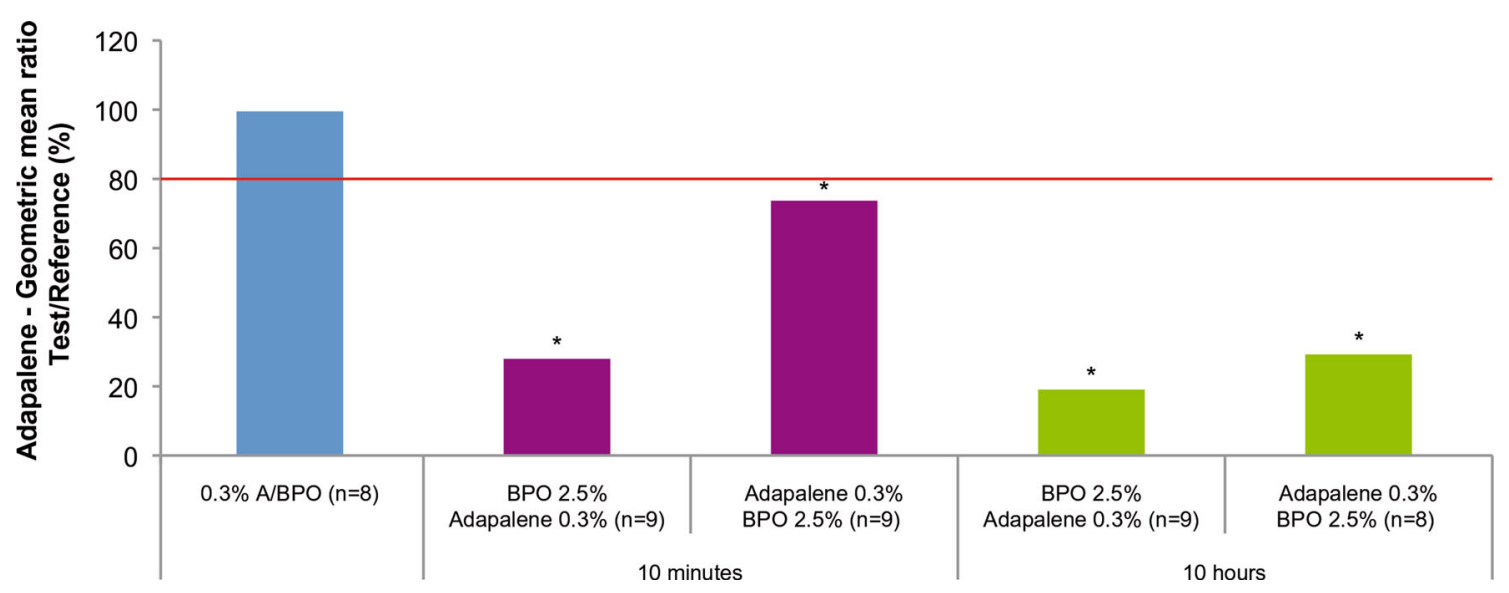

Fig. 5 Adapalene: comparison between treatment regimens (geometric mean ratio, \%). Asterisk outside the acceptance interval of $80-125 \%(<80 \%)$

\section{Adapalene Release}

Figure 1 illustrates the total penetrated adapalene for $0.3 \% \mathrm{~A} / \mathrm{BPO}$. Skin penetration of adapalene in $0.3 \% \mathrm{~A} / \mathrm{BPO}$ gel was more than three times higher than in $0.1 \% \mathrm{~A} / \mathrm{BPO}$ gel. This may be explained in part by the sensitivity of the limits of analytical method that my underestimate the concentration of adapalene in $0.1 \% \mathrm{~A} / \mathrm{BPO}$ gel.

Based on the bioequivalence acceptance criterion, the results showed that all free-combination regimens were different from
$0.3 \% \mathrm{~A} / \mathrm{BPO}$ (Fig. 5). The fixed-combination $0.3 \% \mathrm{~A} / \mathrm{BPO}$ gel showed higher adapalene release compared to all free combinations of monad formulations.

\section{BPO-eq Release}

Figure 3 illustrates the total penetrated BPO-eq for $0.3 \% \mathrm{~A} / \mathrm{BPO}$. The regimen adapalene $0.3 \%$ for $10 \mathrm{~h}$ followed by BPO 2.5\% showed lower $\mathrm{BPO}-\mathrm{eq}$ release when compared to that observed for $0.3 \% \mathrm{~A} / \mathrm{BPO}$ (Fig. 6). 


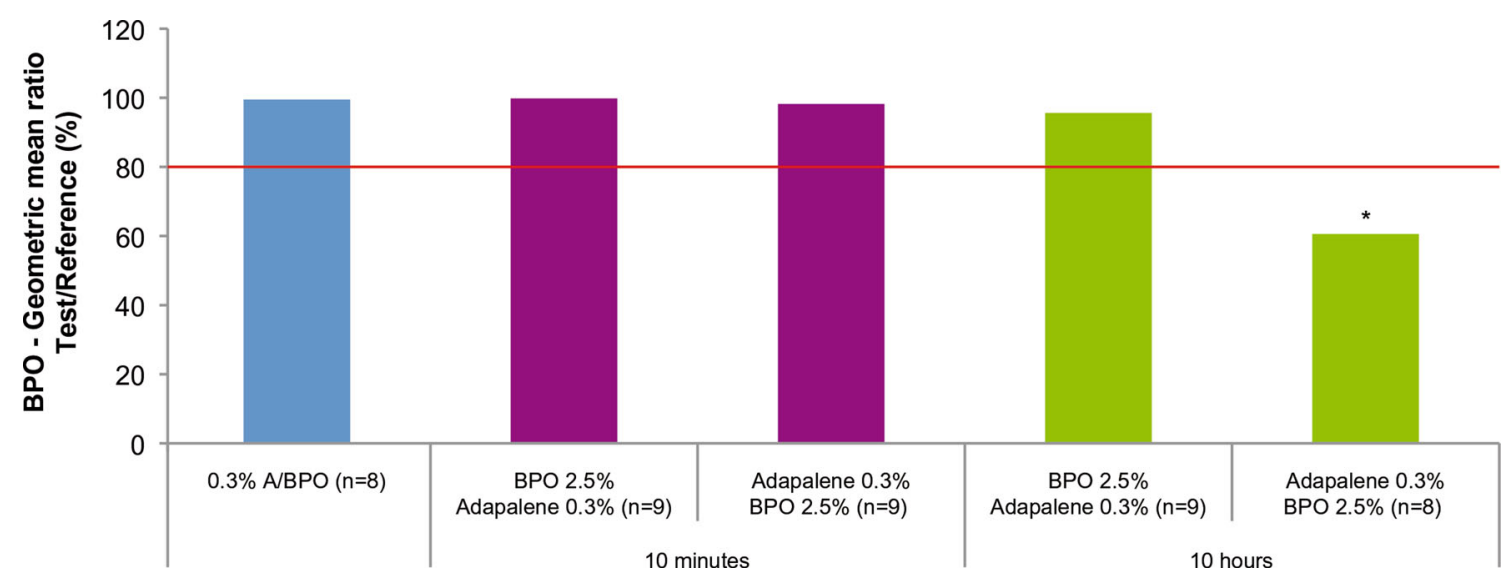

Fig. 6 BPO-eq: comparison between treatment regimens (geometric mean ratio, \%). Asterisk outside the acceptance interval of $80-125 \%(<80 \%)$

\section{DISCUSSION}

The studies described in this article investigated the effect of different treatment regimens on the percutaneous absorption of adapalene $(0.1 \%$ and $0.3 \%)$ gel and BPO $2.5 \%$ gel in ex vivo human skin.

Comparison between the different treatment regimens was performed using the geometric mean ratio of test/reference treatment approach, since quantities recovered in the skin in this kind of experiment generally show a distribution skewed to the right and logarithmic transformation of the data normalizes the distribution (making it symmetrical). Moreover, a geometric mean of different ratios has the advantage of being the same as the ratio of different geometric means, a property that arithmetic means do not have.

Comparison of the two fixed combinations demonstrated more than three times higher absorption of adapalene in the $0.3 \% \mathrm{~A} / \mathrm{BPO}$ regimen versus $0.1 \% \mathrm{~A} / \mathrm{BPO}$. In previous clinical studies on adapalene, it was demonstrated that $0.3 \% \mathrm{~A} / \mathrm{BPO}$ gel resulted in higher efficacy compared to $0.1 \% \mathrm{~A} / \mathrm{BPO}$ in the treatment of severe inflammatory acne $[22,25]$. The higher concentration of adapalene in the $0.3 \% \mathrm{~A} / \mathrm{BPO}$ gel and the resulting higher absorption may explain the higher clinical efficacy. Moreover, the higher concentration of adapalene did not lead to lower safety since both $0.3 \% \mathrm{~A} / \mathrm{BPO}$ and $0.1 \% \mathrm{~A} / \mathrm{BPO}$ were safe and well tolerated [25].

The total amount of penetrated adapalene was higher after the fixed combinations $0.1 \%$ $\mathrm{A} / \mathrm{BPO}$ and $0.3 \% \mathrm{~A} / \mathrm{BPO}$ compared to that of the free-combination regimens. The geometric mean ratios were all out of the acceptance interval of bioequivalence limits (80-125\%), indicating that all four free-combination regimens were different from $0.1 \% \mathrm{~A} / \mathrm{BPO}$ and $0.3 \% \mathrm{~A} / \mathrm{BPO}$, with higher adapalene release delivered by the fixed combinations versus any of the other application regimens. The low level of adapalene in the free-combination regimens may be due to the creation of a physical barrier on the stratum corneum by BPO combined with the slow release of adapalene.

The results of clinical studies indicated that fixed combination of $\mathrm{A} / \mathrm{BPO}$ is more advantageous compared to the free combinations of its monads in terms of efficacy and patient satisfaction [17-21]. Our in vitro results showing higher release of adapalene in the fixed combination than in its monads may explain the higher clinical efficacy. 
Comparison of the two fixed combinations did not reveal differences in the absorption of BPO-eq between 0.1\% A/BPO and 0.3\% A/BPO.

The total amount of penetrated BPO-eq was not modified in regimens where BPO $2.5 \%$ was applied first nor for adapalene $0.3 \%$ for $10 \mathrm{~min}$ followed by the BPO $2.5 \%$ regimen. However, low BPO-eq levels were recovered when adapalene $0.1 \%$ was applied first and for adapalene $0.3 \%$ followed $10 \mathrm{~h}$ later by $\mathrm{BPO}$ $2.5 \%$. In these regimens, the geometric mean ratio was out of the acceptance interval limits with lower BPO-eq release delivered by these regimens versus the fixed combinaison regimens. This could be explained by the creation of a physical barrier on the stratum corneum by adapalene preventing the absorption of BPO.

A limitation of these in vitro studies was the single application of the treatment regimens on the skin samples. Moreover, such studies cannot follow the bioequivalence rule of $80-125 \%$ by using $90 \%$ confidence intervals (the entire interval having to be within these limits), due to the small sample sizes. It is not possible to conclude equivalence because of variability in those studies, even if there is strict equality. Instead, these studies used the point estimate to be within $80-125 \%$ in order to conclude no difference. However, we found this to be a better rule than testing for differences by statistical tests.

Overall, the results of these in vitro studies indicated that fixed combination $0.3 \% \mathrm{~A} / \mathrm{BPO}$ is better than $0.1 \% \mathrm{~A} / \mathrm{BPO}$ gel, and both fixed-combination gels showed higher release of adapalene than its monads, and higher BPO release (according to treatment conditions) than its monad. The high adapalene penetration and concentration in the skin may explain the higher efficacy observed in the clinic with the fixed combination $0.3 \% \mathrm{~A} / \mathrm{BPO}$.

\section{CONCLUSION}

In conclusion, these in vitro studies demonstrate that fixed-combination A/BPO gels provide optimal percutaneous absorption of the active compounds compared to free-combination regimens of monad formulations of adapalene $0.1 \%$, adapalene $0.3 \%$, and BPO 2.5\%. The higher concentration of adapalene in the $0.3 \% \mathrm{~A} / \mathrm{BPO}$ gel and the resulting higher absorption may explain the higher efficacy in the clinic.

\section{ACKNOWLEDGEMENTS}

Sponsorship and article processing charges for this study were funded by Galderma R\&D. Editorial assistance in the preparation of this manuscript was provided by $S$. P. Georgantopoulos, Ph.D., of Galderma R\&D. All named authors meet the International Committee of Medical Journal Editors (ICMJE) criteria for authorship for this manuscript, take responsibility for the integrity of the work as a whole, and have given final approval to the version to be published. All authors had full access to all of the data in this study and take complete responsibility for the integrity of the data and accuracy of the data analysis.

Disclosures. Osman-Ponchet Hanan is an employee of Galderma R\&D. Sevin Karine is an employee of Galderma R\&D. Gaborit Alexandre is an employee of Galderma R\&D. Wagner Nathalie is an employee of Galderma R\&D. Poncet Michel is an employee of Galderma R\&D.

Compliance with Ethics Guidelines. This article does not contain any new studies with human or animal subjects performed by any of the authors. 
Open Access. This article is distributed under the terms of the Creative Commons Attribution-NonCommercial 4.0 International License (http://creativecommons.org/licenses/ by-nc/4.0/), which permits any noncommercial use, distribution, and reproduction in any medium, provided you give appropriate credit to the original author(s) and the source, provide a link to the Creative Commons license, and indicate if changes were made.

\section{REFERENCES}

1. Bhate K, Williams HC. What's new in acne? An analysis of systematic reviews published in 2011-2012. Clin Exp Dermatol. 2014;39:273-7.

2. Tan JK, Bhate K. A global perspective on the epidemiology of acne. $\mathrm{Br} \mathrm{J}$ Dermatol. 2015;172(Suppl 1):3-12.

3. Kligman AM. An overview of acne. J Invest Dermatol. 1974;62:268-87.

4. Thiboutot D, Gollnick H, Bettoli V, et al. Global alliance to improve outcomes in acne. New insights into the management of acne: an update from the Global Alliance to Improve Outcomes in Acne group. J Am Acad Dermatol. 2009;60(Suppl 5):S1-50.

5. Gollnick H, Cunliffe W, Berson D, et al. Global alliance to improve outcomes in acne. Management of acne: a report from a Global Alliance to Improve Outcomes in Acne. J Am Acad Dermatol. 2003;49(Suppl 1):S1-37.

6. Nast A, Rosumeck S, Sammain A, Sporbeck B, Rzany B. Methods report on the development of the European S3 guidelines for the treatment of acne. J Eur Acad Dermatol Venereol. 2012;26(Suppl 1):e1-41.

7. Brogden RN, Goa KE. Adapalene: a review of its pharmacological properties and clinical potential in the management of mild to moderate acne. Drugs. 1997;53:511-9.

8. Michel S, Jomard A, Demarchez M. Pharmacology of adapalene. Br J Dermatol. 1998;139(Suppl 52):3-7.

9. Shroot B, Michel S. Pharmacology and chemistry of adapalene. J Am Acad Dermatol. 1997;36:S96-103.
10. Thiboutot D, Arsonnaud S, Soto P. Efficacy and tolerability of adapalene $0.3 \%$ gel compared to tazarotene $0.1 \%$ gel in the treatment of acne vulgaris. J Drugs Dermatol. 2008;7(Suppl 6):s3-10.

11. Cunliffe WJ, Caputo R, Dreno B, et al. Clinical efficacy and safety comparison of adapalene gel and tretinoin gel in the treatment of acne vulgaris: Europe and US multicenter trials. J Am Acad Dermatol. 1997;36:S126-34.

12. Pariser DM, Westmoreland P, Morris A, et al. Long-term safety and efficacy of a unique fixed-dose combination gel of adapalene $0.1 \%$ and benzoyl peroxide $2.5 \%$ for the treatment of acne vulgaris. J Drugs Dermatol. 2007;6:899-905.

13. Pariser DM, Thiboutot DM, Clark SD, et al. The efficacy and safety of adapalene gel $0.3 \%$ in the treatment of acne vulgaris: a randomized, multicenter, investigator-blinded, controlled comparison study versus adapalene gel $0.1 \%$ and vehicle. Cutis. 2005;76:145-51.

14. Thiboutot D, Pariser DM, Egan N, et al. Adapalene gel $0.3 \%$ for the treatment of acne vulgaris: a multicenter, randomized, double-blind, controlled, phase III trial. J Am Acad Dermatol. 2006;54:242-50.

15. Weiss JS, Thiboutot DM, Hwa J, Liu Y, Graeber M. Long-term safety and efficacy study of adapalene 0.3\% gel. J Drugs Dermatol. 2008;7(Suppl 6):s24-8.

16. Sittart JA, Costa A, Mulinari-Brenner F, Follador I, Azulay-Abulafia L, Castro LC. Multicenter study for efficacy and safety evaluation of a fixed dose combination gel with adapalene $0.1 \%$ and benzoyl peroxide $2.5 \%$ (Epiduo $^{\circledR}$ for the treatment of acne vulgaris in Brazilian population. An Bras Dermatol. 2015;90:1-16.

17. Thiboutot DM, Weiss J, Bucko A, et al. Adapalene-benzoyl peroxide, a fixed-dose combination for the treatment of acne vulgaris: results of a multicentre, randomized double-blind, controlled study. J Am Acad Dermatol. 2007;57:791-9.

18. Gollnick HP, Draelos Z, Glenn MJ, et al. Adapalene-benzoyl peroxide, a unique fixed-dose combination topical gel for the treatment of acne vulgaris: a transatlantic, randomized, double-blind, controlled study in 1670 patients. Br J Dermatol. 2009;161:1180-9.

19. Gold LS, Tan J, Cruz-Santana A, et al. A North American study of adapalene-benzoyl peroxide combination gel in the treatment of acne. Cutis. 2009;84:110-6. 
20. Tan J, Gollnick HP, Loesche C, Ma YM, Gold LS. Synergistic efficacy of adapalene $0.1 \%$-benzoyl peroxide $2.5 \%$ in the treatment of 3855 acne vulgaris patients. J Dermatol Treat. 2011;22:197-205.

21. Eichenfield LE, Jorizzo JL, Dirschka T, et al. Treatment of 2,453 acne vulgaris patients aged 12-17 years with the fixed-dose adapalene-benzoyl peroxide combination topical gel: efficacy and safety. J Drugs Dermatol. 2010;9:1395-401.

22. Stein Gold L, Weiss J, Rueda MJ, Liu H, Tanghetti E. Moderate and severe inflammatory acne vulgaris effectively treated with single-agent therapy by a new fixed-dose combination adapalene $0.3 \% /$ benzoyl peroxide $2.5 \%$ gel: a randomized, double-blind, parallel-group, controlled study. Am J Clin Dermatol. 2016;17:293-303.
23. Skelly JP, Shah VP, Maibach HI, et al. FDA and AAPS report of the workshop on principles and practices of in vitro percutaneous penetration studies: relevance to bioavailability and bioequivalence. Pharm Res. 1987;4:265-7.

24. Zeichner JA, Bhatt V, Pillai R. In vitro percutaneous absorption of benzoyl peroxide from three fixed combination acne formulations. J Clin Aesthet Dermatol. 2013;6:19-22.

25. Weiss J, Stein Gold L, Leoni M, Rueda MJ, Liu H, Tanghetti E. Customized single-agent therapy management of severe inflammatory acne: a randomized, double-blind, parallel-group, controlled study of a new treatment-adapalene $0.3 \%$-benzoyl peroxide $2.5 \%$ gel. J Drugs Dermatol. 2015;14:1427-35. 